\title{
The United Kingdom pacing and cardiovascular events (UKPACE) trial
}

Published guidelines in the United Kingdom ${ }^{1}$ and North America $^{2}$ recommend the routine use of physiological pacing modes, in preference to fixed rate ventricular pacing, for patients with high grade atrioventricular (AV) block. Optimal pacing includes the restoration of AV synchrony and the provision of rate adaptation whenever possible. Despite this, in the United Kingdom in 1995 some $40 \%$ of patients paced for high grade AV block received fixed rate ventricular (VVI) pacing systems (National Pacemaker Database, 1996). Most paced patients are elderly (mean age 73.3 years) and the figures suggest the widespread practice of agism in pacemaker mode selection, with a much higher proportion of physiological pacing systems implanted in younger patients. In those under 70 , only $11.8 \%$ received VVI pacing while in older patients the figure was $46 \cdot 8 \%$ (National Pacemaker Database, 1996). Current practice is thought to reflect uncertainty as to whether optimal pacing is appropriate or cost effective for all of the - predominantly elderly-paced population. ${ }^{34}$

Both dual chamber ${ }^{5-7}$ and rate adaptive single chamber ${ }^{8-10}$ pacing have been shown to offer benefits compared with fixed rate ventricular pacing in terms of improved haemodynamics, increased treadmill exercise tolerance, and reduced symptoms; however, it is not clear to what extent these changes translate in to clinical benefit for the typical patient. ${ }^{11}$ Quality of life studies have shown conflicting results although there is considerable evidence of patient preference for physiological pacing modes. ${ }^{12}$ Much of the clinical data supporting the use of physiological pacing is derived from short term studies of relatively small numbers of patients, often younger than the average. In many instances, crossover study designs have been used in patients who have already been fitted with physiological pacing systems and who were, presumably, pre-selected as being more likely to benefit from them. ${ }^{11}$

In patients with sinus node disease, there is some evidence that physiological pacing may preferentially reduce cardiovascular morbidity and mortality ${ }^{1314}$ but there are only very limited data pertaining to high grade AV block. There is a suggestion of a survival benefit in patients with pre-existing heart failure ${ }^{15} 16$ but this is derived from retrospective studies that may exaggerate the benefits of physiological pacing owing to the inevitable effect of selection bias. Physiological pacing systems are more likely to be implanted in younger and fitter patients and their more favourable outcomes may not be solely because of device selection.

The financial implications of prescribing the optimal pacing mode have attracted much attention. The additional hardware cost alone might increase pacing costs by $75 \%{ }^{4}$ However, a recent cost-benefit analysis suggested that the additional cost at implantation may be recouped after three years if the subsequent savings from reduced morbidity and disability are considered. ${ }^{17}$ Once again, the data are drawn from retrospective studies and interpretation is hampered by the incalculable effect of selection bias.

In the absence of convincing data to the contrary, physicians may feel that the benefits of optimal pacing are less likely to be realised by elderly patients who pursue sedentary lifestyles or who are apparently limited by coexisting cardiac or non-cardiac pathology. Paradoxically, it may be that such patients have much to gain from the superior haemodynamics of optimal pacing in terms of functional capacity and quality of life, ${ }^{11}$ in addition to the possibility of reduced cardiovascular morbidity and improved survival.

\section{UKPACE trial}

There is widespread recognition of the urgent need for a prospective randomised trial to resolve these issues and determine appropriate evidence based practice. ${ }^{3}{ }^{11} 18-20$ Against this background, the United Kingdom Pacing and Cardiovascular Events (UKPACE) trial aims to evaluate the long term clinical impact and cost-utility of dual chamber pacing compared with fixed rate and rate adaptive single chamber pacing in patients $\geqslant 70$ years with high grade AV block.

\section{DESIGN}

The UKPACE trial will randomly allocate 2000 patients $\geqslant 70$ years with high grade (second degree or complete) AV block undergoing first pacemaker implantation to receive a VVI $(25 \%)$, VVIR $(25 \%)$ or DDD $(50 \%)$ pacemaker. The randomisation procedure will use a centralised "interactive voice recording" telephone service, available 24 hours a day. A dynamic allocation algorithm will be used to maintain balanced allocation of pacing modes for older and younger patients within each centre, as well as in the trial overall. Patients with established atrial fibrillation will be excluded but those in whom it has been present for less than three months may be considered if sinus rhythm is restored and maintained following cardioversion. Patients with severe cognitive dysfunction, total immobility, class IV heart failure or advanced malignancy will be also be excluded. Participating centres will be urged to include all eligible patients (subject to written informed consent), and a registry of all patients undergoing first pacemaker implantation will be kept in each centre to ensure compliance. This will be monitored actively and checked against the National Pacemaker Database to ensure that the trial participants are unselected and truly representative. Reasons will be sought for the exclusion of any eligible patients.

\section{BASELINE ASSESSMENT}

Baseline assessment will include history, clinical examination, chest $x$ ray, haemoglobin, serum creatinine, and thyroid function tests. Exercise capacity will be determined by a six minute corridor walk. ${ }^{21}$ This is simply a measure of the distance walked up and down a marked $33 \mathrm{~m}$ passage, without encouragement, during six minutes. Quality of life will be assessed using a composite questionnaire comprising two widely used generic instruments, the SF- 
36 (UK version) ${ }^{22}$ and the EuroQoL EQ-5D. ${ }^{23}$ These have been selected as they are reliable and well validated, with ample normative data, and they can both be administered within a few minutes by personnel with minimal training.

\section{IMPLANT PROCEDURE}

The choice of pacemaker (within the randomised category) will be made by the investigator and implantation will follow standard practice. Patients randomised to receive DDD pacing may be given devices with sensor driven rate adaptation (DDDR), mode switching capability or both, as deemed appropriate by the implanting physician. Procedure duration and screening time will be recorded and retrograde (ventriculoatrial) conduction will be assessed. Periprocedural complications will be recorded and costed, as will details of the duration of hospital stay and use of resources.

\section{PACEMAKER PROGRAMMING}

Pacemaker programming will be left to the clinical judgment of the investigator although standard initial mode selection (VVI, VVIR or DDD) as randomised is mandatory. Broad guidelines are suggested for DDD pacemaker settings: AV delay $150 \mathrm{~ms}$, rate adaptive $\mathrm{AV}$ shortening to $75 \mathrm{~ms}$, and lower and upper rate limits of 60 beats $/ \mathrm{min}$ and 125 beats/min, respectively. Similarly, for VVIR pacemakers a rate range of 70 beats $/ \mathrm{min}$ to 125 beats $/ \mathrm{min}$ is suggested, and for VVI pacemakers 70 beats $/ \mathrm{min}$. Programmed settings will be recorded at discharge and at each follow up visit. Interim reprogramming will be noted in the patient diary and reviewed at the subsequent follow up visit.

\section{FOLLOW UP AND OUTCOME MEASURES}

All patients will be followed for a minimum of three years. Outcome measures to be assessed will include quality of life, exercise capacity, cardiovascular events, and cost-utility. The only end point will be all cause mortality. To ensure notification of all deaths, details of all eligible patients will be registered with the Office for National Statistics (formerly OPCS). Follow up visits will be scheduled at 1, 4, 10,16, and 36 months and these will be combined with routine checks of pacemaker function.

A diary will be issued to all randomised patients, in which details of any general practitioner or hospital visits will be recorded to supplement information obtained at follow up. This will permit a more complete assessment of overall morbidity and use of health care resources, and will contribute to the cost-utility analysis. Physicians attending the patient will be asked to inform the follow up centre of specified cardiovascular events or other significant medical events as soon as they occur.

Specified cardiovascular events will include new or significantly worsening heart failure, suspected pacemaker syndrome, revision of pacing system, stroke, transient ischaemic attack or other thromboembolism, atrial fibrillation, new onset angina, and myocardial infarction. Other medical events to be reported will include pacemaker related complications, any procedure requiring hospitalisation, any other serious event or event of concern to the investigator. In the event of pacemaker syndrome or other pacemaker related complications, the decision to upgrade will be left to the discretion of the clinician. Suspected pacemaker syndrome will, however, prompt a more detailed clinical assessment including the administration of a pacemaker syndrome questionnaire. ${ }^{24}$ This assessment will be repeated at subsequent follow up visits to determine the effect of any therapeutic intervention. Cardiovascular and other significant medical events will be costed as part of the cost-utility assessment and a sensitivity analysis will be performed.
OTHER STUDIES

At least three major "sub-studies" will be undertaken in selected patients: a comparative nuclear assessment of left ventricular function, Holter recording to assess the prevalence of atrial arrhythmia during follow up, and a more detailed assessment of quality of life and cognitive function.

\section{PILOT EXPERIENCE}

A pilot study to assess feasibility was initiated in August 1995. During a mean recruitment period of nine months, 168 patients were enrolled between three centres. This represented $53.3 \%$ of the eligible population ( $\geqslant 70$ years, high grade AV block) in those centres and $18.9 \%$ of their total pacing practice. The study, which was favourably received by the participating patients and physicians, suggests that the proposal to recruit 2000 patients over a one year period will be feasible with extension of the study to some 40 additional centres.

\section{REPORTING}

It is anticipated that recruitment will be completed towards the end of 1997. Preliminary analysis and presentation of results is planned when all patients have completed at least one year of follow up, with final analysis after a further two years. Active follow up within the trial will then cease but periodic review of late deaths will continue using returns from the Office for National Statistics.

\section{Discussion}

The advent of large scale prospective randomised trials to the field of cardiac pacing is a recent phenomenon and attention has focused on the practical and ethical problems posed. ${ }^{25}$ Widely differing practice between different centres and the departure from published guidelines suggest the existence of a state of confused collective equipoise ${ }^{26}$ in the pacing community with respect to the case for physiological pacing in the elderly. Financial constraints may also influence current practice but if rationing is to be acceptable, it must be explicit and priorities should reflect the clinical needs of patients and the costutility of alternative treatments.

A case has been made for a prospective observational study, involving many centres with divergent practices, to overcome the difficulties posed by randomisation. ${ }^{25}$ Outcomes research may make a useful contribution, but the possibility of selection bias being imposed by referring or implanting physicians is inevitable, and the ethical issues are no less real. Hypotheses formed from retrospective data and the clinical intuition of implanting physicians should be subjected to the rigorous test of a carefully designed prospective randomised trial to provide evidence based guidelines and ensure an even standard of care for patients.

The ethical issues raised by the UKPACE trial have received careful consideration and the protocol has been approved by over 20 independent ethics committees. Only $25 \%$ of randomised patients will receive fixed rate ventricular pacing, compared with an overall figure of $46.8 \%$ for the same age group in the UK in 1995 . Conversely, $50 \%$ will receive dual chamber devices, compared with an agematched UK figure of $41 \%$ for 1995 . Randomisation will thus increase the overall provision of physiological pacing during the recruitment phase. In any event, all patients will be subject to careful scrutiny during follow up and those with severe intolerance of the prescribed mode may be upgraded.

Concurrent with the UKPACE trial, two other large scale prospective randomised pacemaker trials are also 
under way in Canada and the USA. ${ }^{19}$ The Canadian Trial of Physiologic Pacing (CTOPP) aims to compare ventricular pacing (VVI or VVIR) with physiological pacing (DDD, DDDR, AAI or AAIR) in 2450 patients aged $\geqslant 18$ years receiving their first pacemaker implant for either sinus node disease or AV block. The exclusion criteria and outcome measures to be assessed are broadly similar to UKPACE. CTOPP has completed recruitment and is likely to report at least a year before UKPACE but the two studies will complement each other. The Mode Selection Trial (MOST), currently recruiting in the USA, will address similar issues in patients with sick sinus syndrome. Two thousand patients aged $>21$ years will be implanted with a DDDR pacing system and randomised to programming in either VVIR or DDDR mode. The trial aims to evaluate the benefits of DDDR pacing in terms of event free survival, quality of life, and cost effectiveness.

The results of the UKPACE trial and others in progress should provide invaluable evidence to guide the future practice of cardiac pacing and resolve many of the uncertainties currently faced by implanting physicians and the purchasers and providers of health care.

Contacts-Anyone wishing to participate in the UKPACE trial or requiring further details is invited to contact Dr W D Toff (tel: 0116250 2500, fax: 0116250 2501) or Dr J D Skehan (tel: 0116256 3888, fax: 0116 $2314751)$.

The UKPACE trial is funded by a grant from the Medical Research Council and supported by the Council of the British Pacing and Electrophysiology Group. Additional hardware costs are being subsidised by the following pacemaker manufacturers and suppliers: Biotronik UK Ltd, CardioCare Ltd, CPI Inc, ELA Medical UK Ltd, Intermedics, Medtronic Ltd, St Jude Medical UK Ltd, Sorin Biomedica (UK) Ltd, Telectronics Ltd, Vitatron UK Ltd. Additional funding for sub-studies has been provided by the British Heart Foundation, the NHS Research and Development Directorate, and the Glenfield Hospital Research Fund.

WILIIAM D TOFF

J DOUGLAS SKEHAN DAVID P DE BONO

Department of Cardiology,

Glenfield Hospital,

Leicester, UK

A J CAMM

Department of Cardiological Sciences,

St George's Hospital Medical School,

London, UK

1 Clarke M, Sutton R, Ward D, Camm AJ, Rickards A, Ingram A, et al. Recommendations for pacemaker prescription for symptomatic bradycardia. Br Heart f 1991;66:185-91.

2 Dreifus LS, Fisch C, Griffin JC, Gillette PC, Mason JW, Parsonnet V. Guidelines for implantation of cardiac pacemakers and antiarrhythmia devices. A report of the American College of Cardiology/American Heart Association Task Force on Assessment of Diagnostic and Therapeutic Cardiovascular Procedures (Committee on Pacemaker Implantation) Circulation 1991;84:455-67.

3 Petr MC Who needs dul chamber pacing? BMF 1993:307:215-16.

4 de Belder MA, Linker NJ, Jones S, Camm AJ, Ward DE. Cost implications of the British Pacing and Electrophysiology Group's recommendations or pacing. BMF 1992;305:861-5.

5 Kruse I, Arnman K, Conradson T-B, Rydén L. A comparison of the acute and long-term haemodynamic effects of ventricular inhibited and atria synchronous ventricular inhibited pacing. Circulation 1982;65:846-55.

6 Perrins EJ, Morley CA, Chan SL, Sutton R. Randomised controlled trial of physiological and ventricular pacing. Br Heart $\mathcal{f} 1983 ; 50: 112-17$

7 Boon NA, Frew AJ, Johnston JA, Cobbe SM. A comparison of symptom and intra-arterial ambulatory blood pressure during long term dual chamber atrioventricular synchronous (DDD) and ventricular demand (VVI) pacing. Br Heart $f$ 1987;58:34-9.

8 Benditt DG, Mianulli M, Fetter J, Benson DW, Dunnigan A, Molina E, et al. Single-chamber cardiac pacing with activity-initiated chronotropic response: evaluation by cardiopulmonary exercise testing. Circulation 1987;75:184-91.

9 Lipkin DP, Buller N, Frenneaux M, Ludgate L, Lowe T, Webb SC, et al. Randomised crossover trial of rate responsive Activitrax and conventional fixed rate ventricular pacing. Br Heart 7 1987;58:613-16.

10 Smedgård P, Kristensson B-E, Kruse I, Rydén L. Rate-responsive pacing by means of activity sensing versus single rate ventricular pacing: a doubleby means of activity sensing versus single rate ve
blind cross-over study. $P A C E$ 1987;10:902-15.

11 McComb JM, Bexton RS. Permanent pacemakers and the elderly: concerns, costs and benefits. Br Heart f 1995;74:9-10

12 Linde C. How to evaluate quality-of-life in pacemaker patients: problems and pitfalls. PACE 1996;19:391-7.

13 Rosenqvist $M$, Brandt J, Schuller $H$. Long-term pacing in sinus node disease; the effects of stimulation mode on cardiovascular morbidity and mortality. Am Heart $\mathcal{F}$ 1988;116:16-22.

14 Camm J, Katritsis D. Ventricular pacing for sick sinus syndrome-a risky business? PACE 1990;13:695-9.

15 Alpert MA, Curtis JJ, Sanfelippo JF, Flaker GC, Walls JT, Mukerii V, et al Comparative survival after permanent ventricular and dual chamber pacing for patients with chronic high degree atrioventricular block with and without preexistent congestive heart failure. $7 \mathrm{Am}$ Coll Cardiol 1986;7: 925-32.

16 Linde-Edelstam C, Gullberg B, Norlander R, Pehrsson SK, Rosenqvist M, Rydén L. Longevity in patients with high degree atrioventricular block paced in the atrial synchronous or the fixed rate ventricular inhibited mode. PACE 1992;15:304-13.

17 Sutton R, Bourgeois I. Cost-benefit analysis of single- and dual-chamber pacing for sick sinus syndrome and atrio-ventricular block. Eur Heart $\mathscr{f}$ 1996;17:542-82.

18 Parsonnet V. The cost-effectiveness of dual chamber pacing. Eur Heart $\mathcal{f}$ 1996;17:495-6.

19 Lamas GA. Pacemaker mode selection and survival: a plea to apply the principles of evidence based medicine to cardiac pacing practice [editorial] Heart 1997;78:218-20.

20 Payne GE, Skehan JD. Issues in cardiac pacing: can agism be justified? $\mathrm{Br}$ Heart F 1994;72:102-3.

21 Guyatt G, Sullivan MJ, Thompson PJ, Fallen EL, Pugsley SO, Taylor DW, et al. The 6-minute walk: a new measure of exercise capacity in patients with chronic heart failure. Can Med Assoc f 1985;132:919-23.

22 Ware JE. SF-36 health survey: manual and interpretation guide. Boston Health Institute, New England Medical Centre, 1993.

23 EuroQol Group. EuroQol - a new facility for the measurement of healthrelated quality of life. Health Policy 1990;16:199-208.

24 Sulke N, Dritsas A, Bostock J, Wells A, Morris R, Sowton E. Subclinical pacemaker syndrome: a randomised study of symptom free patients with ventricular demand (VVI) pacemakers upgraded to dual chamber devices. Br Heart $¥$ 1992;67:57-64.

25 Ovsyshcher IE. Matching optimal pacemaker to patient: do we need a large scale clinical trial of pacemaker mode selection? $P A C E$ 1995;18:1845-52.

26 Lilford RJ, Jackson J. Equipoise and the ethics of randomisation. $\mathcal{f} R$ Soc Med 1995;88:552-9. 